\title{
Palavra dita é flecha lançada: ato jurídico e linguagem em Oswald Ducrot
}

\author{
Julio Cesar Machado \\ Docente da Universidade do Estado de Minas Gerais, Brasil \\ https://orcid.org/0000-0003-0364-3370
}

Resumo: este artigo retoma a crítica de Paul Henry sobre a noção de ato jurídico ducrotiana, apresentado pelo autor à guisa de exemplos estranhos à espessura linguísticoargumentativa deste fenômeno. Nosso objetivo é debruçar-se sobre uma abordagem argumentativa do fenômeno semântico nomeado de ato jurídico, refinamento que escapou a Henry, e que o levou a desconsiderar o potencial de ressignificação (semânticotransformador) na língua e na enunciação. Procedimentalmente, descreveremos com maior acuidade teórica, e de modo mais atento, as espessuras do ato jurídico linguístico. Enquanto resultados, trazemos à baila uma abordagem mais cuidadosa da noção de língua, em Ducrot, e uma ideia mais concisa sobre o estruturalismo enunciativo, área de saber em que se inscreve a contradição entre objeto real (sentido ducrotiano, próprio da língua em uso) e objeto de conhecimento (significação ducrotiana, própria da língua fora de uso) que funda a Semântica Argumentativa, objetos sem os quais a crítica henryana não se legitima.

Palavras-chaves: Ato jurídico. Pressuposição. Enunciação. Semântica Argumentativa.

Abstract: this article takes up Paul Henry's critique of the notion of a ducrotian juridical act, presented by the author by way of examples strange to the linguistic-argumentative thickness of this phenomenon. Our goal is to focus on an argumentative approach to the semantic phenomenon called a juridical act, a refinement that escaped to Henry, and which led him to disregard the resignification potential (semantic-transformative) in language and enunciation. Procedurally, we will describe with greater theoretical accuracy, and in a more attentive way, the thicknesses of the linguistic juridical act. As results, we bring up a more careful approach to the notion of language, in Ducrot, and a more concise idea about enunciative structuralism, an area of knowledge in which the contradiction between real object (ducrotian sense, typical of the language in use) is inscribed, and the object of knowledge (ducrotian signification, typical of the language out of use) that founds the Argumentative Semantics, objects without which the henryian criticism is not legitimate.

Keywords: Juridical act. Presuppose. Enunciation. Argumentative Semantics. 


\section{Introdução: o objeto da crítica versus a crítica ao objeto}

Este artigo nasce no interior da crítica de Paul Henry (1977), no livro la mauvais outil: langue, sujet et discours (no Brasil, A ferramenta imperfeita: língua, sujeito $e$ discurso (2013)), ao conceito de ato jurídico de Ducrot (1972), do seu livro Dire et ne pas dire: príncipes de sémantique linguistique (no Brasil, Princípios de Semântica Linguística: dizer e não dizer (1977)). E é por isso que, como gesto de coerência metodológica, que busca preservar o ambiente da crítica, valer-nos-emos principalmente desses dois livros para refletir o objeto da crítica (o ato jurídico segundo Ducrot - que é linguístico, ou intrínseco ao acontecimento) e a crítica ao objeto (o ato jurídico segundo Henry - que, naquela ocasião, é forense, ou extrínseco ao acontecimento), que ao nosso ver são duas abordagens bem distintas.

O objeto da crítica é a seguinte constitutividade de linguagem, nomeada por Ducrot (1977, p. 87-88) de ato jurídico:

Falaremos em ação jurídica quando a atividade se caracterizada por uma transformação das relações legais existentes entre os indivíduos concernidos. [...] Pode-se definir o ato jurídico agora como caso particular da ação jurídica. Esta nova noção é aplicada quando se considera a transformação das relações legais como efeito primeiro da atividade e não como a consequência de um efeito logicamente ou cronologicamente anterior. [...] o enunciado de uma sentença por um magistrado pode ser facilmente considerado como um ato jurídico, porquanto nenhum efeito vem-se intercalar entre a fala do magistrado e a transformação do acusado em condenado - já que é a fala que condena. O mesmo vale para a martelada do leiloeiro num leilão, se considerarmos que ela constitui imediatamente o contrato de venda, obrigando a última pessoa que fez o lance a pagar o preço enunciado, e o vendedor, a aceitar tal preço.

A crítica ao objeto, da qual este artigo se ocupa, é a seguinte discordância de Henry [1977] (2013, p. 90):

Isso significa que cometer um crime não é em si uma ação jurídica mesmo se depende da lei, mas o enunciado de uma sentença por um magistrado é, em compensação, um ato jurídico. Portanto, é mesmo a sociedade que confere ao ato sua natureza e não o ato que é, por si mesmo, de natureza jurídica, do mesmo modo que é a sociedade que confere ao ato de dizer eu prometo um caráter qualificado e, por isso, jurídico. [...] querer a morte de alguém não é um crime, mas sim o fato de ter matado alguém.

De início, é importante marcar a relevância que tal livro de Henry tomou em Linguística, especificamente, em estudos enunciativos. Dentre seus méritos estão, entre outros, os vários rearranjos teóricos sobre pontos criticados por Henry. Tal crítica 
mostrou-se produtiva ao se desdobrar em pesquisas de aprofundamentos na relação entre argumentação, pressuposição e enunciação (por exemplo, ela levou Ducrot à elaboração do conceito de enunciador, que não trataremos aqui, quando da elaboração de uma Teoria Polifônica da Enunciação, no interior da Semântica Argumentativa $)^{1}$. Contudo, não é sobre tais méritos que se debruça este artigo.

Ocupar-nos-emos da inconsistência reflexiva sobre a descrição do ato jurídico, que, por abordagens não profundas em Semântica Argumentativa, precisa ser retomada e melhor descrita naquilo em que de fato opera: a espessura semântica transformacional na língua e no discurso. Tal noção, em Henry, foi criticada por uma metodologia de apresentar exemplos de atos forenses, estranhos à espessura argumentativa do fenômeno dos atos linguístico, E tal incongruência epistemológica (pensa-se criticar um conceito, quando na verdade não se conseguiu descrever o alcance do fenômeno operado por este conceito), justifica nossa pesquisa e reclama uma resposta, mesmo que tardia.

Nesse contexto, nortear-nos-emos por dois objetivos: o primário é debruçar-se sobre um refinamento da concepção jurídico-linguística, que levou Henry a desconsiderar o potencial de ressignificação (semântico-transformador) "na língua" e na enunciação, o que nos conduz a descrever com maior acuidade teórica e de modo mais atento as espessuras do ato jurídico linguístico (enfatizamos que, tal como Henry apresenta, o ato jurídico não é linguístico).

Nosso objetivo secundário, é, à luz da reflexão das constitutividades do ato jurídico ducrotiano, desconsiderado por Henry, trazer à baila uma ideia mais refinada sobre semântica e argumentação, área de saber em que se inscreve a contradição entre objeto real (sentido ducrotiano) e objeto de conhecimento (significação ducrotiana) que funda a Semântica Argumentativa, sofisticação e sutilezas que escaparam a Henry, e sem as quais a crítica não se legitima.

\footnotetext{
1 Alguns autores defendem a organização epistemológica da Semântica Argumentativa em apenas três fases: Standard, Standard Ampliada e Blocos Semânticos. Embora haja muitas outras formas de cadenciar a Semântica Argumentativa, essa tri-visão nos é útil para ilustrar que o livro de Henry foi um dos desarranjos geradores da transição do período Standard (cujo escopo metodológico se ocupa do "argumento para conclusão") para o período Standard Ampliado (cujo escopo metodológico se ocupa também da "polifonia" e dos "topoi").
} 
1. $O$ ato jurídico

Há três coisas que jamais voltam: a flecha lançada, a palavra dita e a oportunidade perdida (provérbio chinês)

O fenômeno do ato jurídico foi arquitetado por forte influência da teoria dos atos de fala e filósofos de Oxford, e, à época, Ducrot (1977, p. 79) já colocava ressalvas quanto a uma reinterpretação dessa concepção teórica. O leitor observará que nos afastamos de uma concepção pragmática de linguagem, no tocante à consideração e reflexão de um universo "alheio à linguagem” (o mundo físico e biológico). Ducrot não separa o "mundo" e a "linguagem" - e isso não significa que "o mundo não exista", senão que "o mundo existe quando significado, e que acontece na e pela linguagem". Como respondeu à Henry, o método de Ducrot para trabalhar o nó "teoria versus prática" possui uma envergadura solidária entre o real (o sentido, produzido pela língua em uso) e o conhecimento do real (a significação, própria da língua fora de uso).

De início, marcamos que o ato jurídico não é operável pelo arcabouço dos "atos de fala", da pragmática de Oxford, mas por um prisma argumentativo, próprio de uma démarche argumentativa que triangula três noções: posto, pressuposto $\mathrm{e}$ encadeamento, minimamente - refinamentos desconsiderados por Henry em sua crítica, como veremos. Uma noção cara à epistemologia ducrotiana, mas que não aprofundaremos aqui, é a pressuposição. Ela possui, em si, constitutividades de ato jurídico, e Ducrot se ocupa dessa exposição. A pressuposição, enquanto ato jurídico, permanece um fenômeno semântico operável pela arquitetura teórica da Semântica Argumentativa (epistemologia criada por Ducrot, inicialmente, e formalizada por Ducrot e Anscombre, secundariamente).

$\mathrm{O}$ ato jurídico linguístico ${ }^{2}$ tem no potlach um dos seus exemplos base. Aquele em que, nas relações intersociais ameríndias, é um "presente-obrigação", isto é, o locutor que enuncia o potlach (certa tribo que dá um presente qualquer a uma outra) transforma a ação jurídica de seu interlocutor (a tribo que recebe o presente), inserindo-a numa relação de retribuir o presente (Ducrot, 1972, p. 88). A significação estrutural basal (fora de enunciações) do potlach é: dar um presente significa, portanto, ter que retribuir o presente. Deontologia social que ecoa, em menor força, em muitas sociedades tradicionais, e até contemporâneas (em cidades do interior do Brasil,

\footnotetext{
$2 \mathrm{Na}$ atualidade da Semântica Argumentativa, as questões do ato jurídico são retomadas pela teoria da l'action en disant (ação dizendo). Conferir esta retomada em nossa obra Cours de Sémantique Argumentative (BEHE et al, 2021) e em Carel e Ribard (2019).
} 
saudar alguém com "bom dia, bom trabalho etc" é obrigar o outro a responder a saudação, mesmo se desconhecidos, para citar um rápido exemplo).

Henry, por sua vez, discorda da hipótese de um ato jurídico que esteja "na" língua, ao contradizer que obrigações dessa natureza não têm natureza na língua, mas dependem de sujeitos que, esses sim, irão atribuir tais obrigações sobre os atos. Podemos dizer que Ducrot pensa o ato jurídico intrínseco à língua (um semantismo que contém em si tanto o dado como a consequência do dado); e Henry pensa o mesmo o ato jurídico extrínseco à língua, porque reclama um sujeito para ser jurídico (o dado tange à língua, e a consequência do dado tange à interpretação do sujeito). Portanto, identifica-se, já aqui, que Henry não partilha da noção de língua ducrotiana, que sempre integrou elementos da fala na língua, e cujo escopo procedimental central sempre foi recuperar marcas da enunciação no enunciado. Como temos dito (MACHADO, 2021b), em Ducrot, “não se pensa 'Estrutura' isolando-a do 'funcionamento da estrutura'. Ou como bem explica o próprio Ducrot (1977, p. 294):

De um lado, a semântica linguística deve ser estrutural. E, de outro, o que fundamenta o estruturalismo em matéria de significação deve levar em conta a enunciação.

O ato jurídico-linguístico reclama percepções técnicas por sobre a pressuposição que não explanaremos aqui ${ }^{3}$. Foquemos apenas em um ponto forte da pressuposição: ela obriga o interlocutor a ser um partícipe da enunciação (a língua prevê - fora do uso - que ser polido ao dizer "Como vai você?" é significar obrigação do outro em corresponder à polidez, com um "vou bem, obrigado, e você?", sob pena de ressignificar-se mal educado, se não responder). A obrigação instaurada no acontecimento enunciativo, acarreta na transformação das relações entre interlocutores. É este o fenômeno transformacional, não pragmático, mas semântico: participar de um diálogo, mesmo como ouvinte, é ser transformado ali, determinado pelas obrigações de dizer ou não-dizer, e conforme se é obrigado a manifestar-se.

\footnotetext{
3 Sugerimos a leitura de nosso trabalho sobre as cinco constitutividades da pressuposição argumentativa: $A$ pressuposição-defeito de Paul Henry e a pressuposição argumentativa de Oswald Ducrot: um fenômeno que insiste e resiste, em Machado (2021a).
} 


\section{Ato jurídico e pressuposição}

A crítica de Henry ao conceito de ato jurídico, como expomos acima, trata-se de uma curtíssima exposição de exemplos. Vamos, aqui, rever com maior acuidade de rigor teórico ducrotiano o que de fato constitui tal fenômeno na língua e no discurso.

Ducrot chama a atenção para o fato de não apenas os postos, mas também os pressupostos possuirem valor de ato jurídico (de potencial transformador das relações entre interlocutores). Isto é, a pressuposição argumentativa estabelece uma deontologia linguística da qual todo pressuposto "impõe obrigações" aos partícipes do discurso, e tal imposição transforma a relação entre os interlocutores:

\section{(1) Esta empresa está vendendo menos.}

Refletiremos, aqui, uma démarche argumentativa (operada pelos conceitos de posto, pressuposto e encadeamento, nesta fase da década de 70).

O posto $(\mathrm{p})$ "Esta empresa está vendendo menos" revela o pressuposto (pp) "Esta empresa já vendeu mais no passado". A sutileza é que esse pressuposto transforma as relações sociais entre interlocutores da empresa, pois, na mera consideração de (1), funcionário, patrão, fornecedor, consumidor, já apresentam, na frase em si, suas relações transformadas entre si, devido ao pressuposto "maior venda" no contraste com o posto "vender menos". Não falamos das consequências acarretadas pelo possível dito, mas da transformação de relações entre interlocutores, previstas "no" possível dito.

Vamos exemplificar, em situações enunciativas (por exemplo, funcionários e chefes), pois, ora, se o patrão enuncia (1) ao seu empregado, isto encadeia, argumentativamente: você pode vender mais, você é melhor que isso, você corre o risco de perder o emprego, é necessário voltar à média de vendas etc; $E$ se o empregado enuncia (1) ao patrão, isto encadeia, argumentativamente: vamos nos esforçar mais, é necessário rever aspectos, é preciso certos investimentos, você é um péssimo patrão (esta, mais rara); e se um mídia enuncia (1) a público em geral, encadeia-se minimamente: falar bemol falar mal de tal empresa, concordar que tal empresa corre riscos, dissertar que tal empresa já não é a mesma etc.

Não importa, nos três exemplos acima, que se desdobram infinitamente, mesmo pensando (1) fora de ocorrências enunciativas, temos já, na língua, a transformação de relações mínima entre interlocutores: os potenciais interlocutores de (1), diretos ou indiretos, preveem mudanças de relações entre si, pela consideração de (1): as 
mudanças de relação podem ser descritas como medo de desemprego, o risco de falência, a carência de lucros e etc, que transformam as relações entre os envolvidos: funcionários, patrões, consumidores, fornecedores etc.

Para Ducrot, nenhuma enunciação é desavisada, gratuita. Dizer é transformar relações, porque o dizer ressignifica interlocutores. Tecnicamente, a enunciação da (pp) de melhor lucro reconfigura e ressignifica as relações entre interlocutores, que tomam consciência, naquele exato acontecimento virtual, das mudanças imediatas (o ato jurídico) e outras que se acarretarão (os encadeamentos: demissões, promoções, realocações, quadro reduzido ou ampliado, mudança de abordagens, redução salarial, exigência de melhor produção etc). Transformações estas baseadas na preservação e perseguição do pressuposto de melhores vendas de outrora. Assim, para Ducrot (1972, p. 108), a pressuposição é “[...] como um poder jurídico dado ao locutor sobre o destinatário".

\section{A transformação do ato jurídico linguístico, de Ducrot versus a interpretação do ato jurídico forense, de Henry}

Após uma abordagem do fenômeno, retomemos agora Henry (2013, p. 90), quando apresentou a seguinte crítica: “cometer um crime não é em si uma ação jurídica, mesmo se depende da lei, mas o enunciado de uma sentença por um magistrado é, em compensação, um ato jurídico". Pela crítica, Henry filia o ato jurídico à dimensão forense (distinta do ato jurídico em Ducrot, de dimensão linguística).

O arcabouço teórico da Semântica Argumentativa, à época - e ainda mais hoje poderia polemizar a tese "cometer um crime" de Henry pela disposição analítica dos dois acontecimentos enunciativos em co-relação: há o acontecimento-posto (que pressupõe: "algo foi cometido"), que se desdobra no acontecimento-interpretação (que subentende ou encadeia: "isso é um crime jurídico, ou não") 4 . Nota-se que o exemplo de Henry não é da língua fora de empregos, mas da língua em um emprego, uma enunciação de um juiz que interpreta um acontecimento anterior.

Tecnicamente, a exposição rápida de Henry sobre este fenômeno produz um efeito de trazer à baila dois conceitos, que se confundem na exposição mesma do autor: ato jurídico forense (o juiz ou a sociedade qualificam o acontecimento "após-

\footnotetext{
${ }^{4} \mathrm{Na}$ atualidade da Semântica Argumentativa (a Teoria dos Blocos Semânticos), os dois acontecimentos de [por / pressupor] e [subentender] são tratados como duas facetas de um mesmo acontecimento, agora pelas noções de primeiro plano e segundo plano, conforme o Cours de Sémantique Argumentative (BEHE et al, 2021).
} 
acontecimento", o que para Ducrot é interpretação) e ato jurídico linguístico, o proposto por Ducrot (“o acontecimento”, em si mesmo, transforma as relações entre seus partícipes, o que não necessariamente é um juízo secundário, interpretação/decisão jurídico-forense). Não existe coincidência teórica nessas duas noções.

Tecnicamente, o ato jurídico linguístico está no acontecimento-posto/pressuposto, o primeiro, onde dizer é ressignificar relações entre interlocutores, e o ato jurídico forense está no acontecimento-interpretação, o segundo, onde, conforme Henry, o juiz decide o que significam as coisas. Como explica Ducrot: (1987 [1969], p. 20):

Se o posto é o que afirmo, enquanto locutor, se o subentendido é o que deixo meu ouvinte concluir, o pressuposto é o que apresento enquanto pertencendo ao domínio comum das duas personagens do diálogo, como o objeto de uma cumplicidade fundamental que liga entre si os participantes do ato de comunicação. Em relação ao sistema de pronomes poder-se-ia dizer que o pressuposto é apresentado como pertencendo ao "nós", enquanto o posto é reivindicado pelo "eu", e o subentendido é repassado ao "tu".

Para Ducrot, o exemplo henryano é descrito assim: alguns locutores (testemunhas?) apresentam o posto "algo passível de ser lícito ou ilícito", que virá a ser subentendido, isto é, interpretado como "crime" ou "não-crime" pelo juiz-ouvinte, enquanto todo o processo reconstitui um domínio comum, o (pp) "algo (grave) aconteceu". A questão é que, em Ducrot, o (pp) "algo (grave) aconteceu”, se julgado ou não por um juiz, "já transformou" as relações entre os interlocutores partícipes deste algo que ocorreu, partícipes que nunca mais serão os mesmos entre si: relações entre vítimas e suspeitos, vítimas e testemunhas, suspeitos e vítimas, suspeito e testemunhas etc.

Conforme a figura abaixo, a qualificação jurídica do ato, em Henry, encontra-se no "tu - subentendido", e a qualificação jurídica do ato, em Ducrot, encontra-se no "nós -pressuposto" (atentando-se para a epistemologia solidária entre posto e pressuposto, em Ducrot). 
Figura 1 - Posto, pressuposto e subentendido

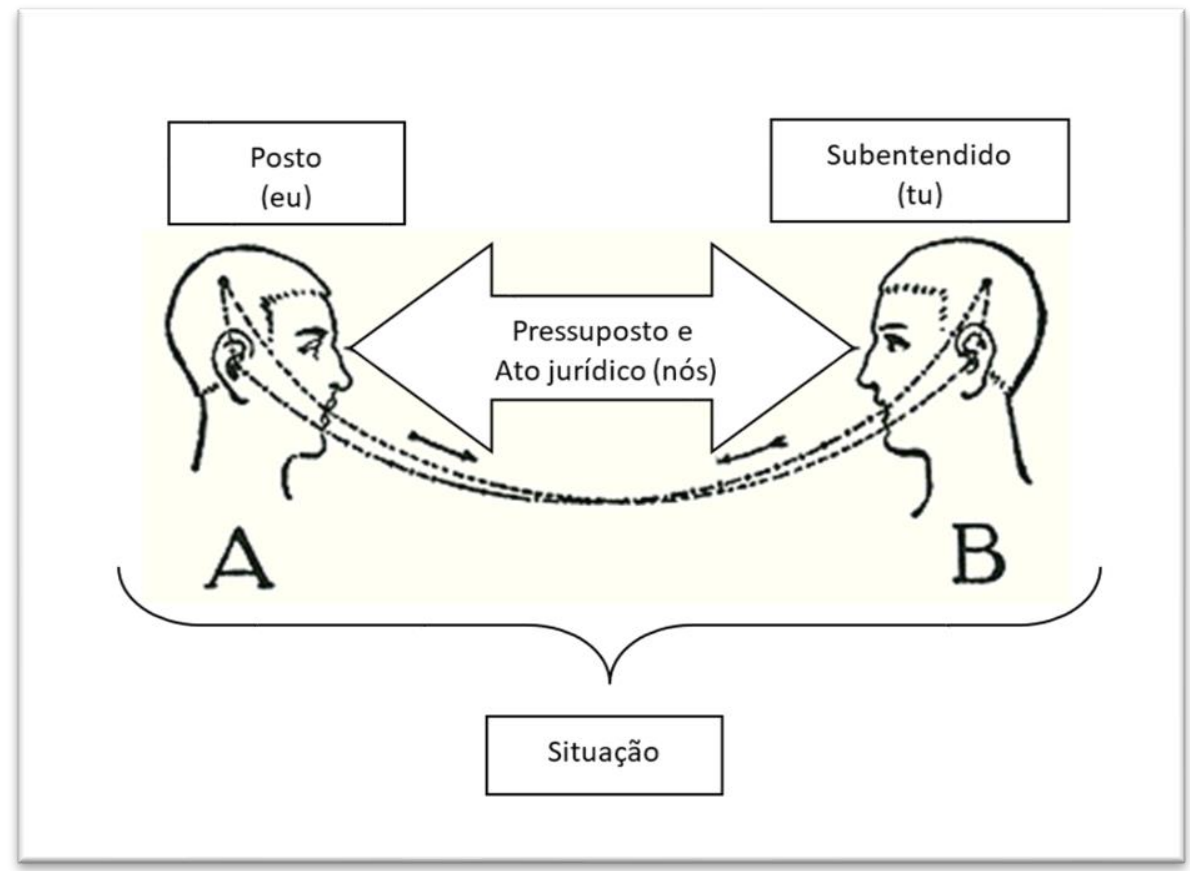

Fonte: Elaboração do autor, baseado em Ducrot (1987, p. 20) e Bally e Sechehaye (1985, p. 27).

\section{Revisão argumentativa de uma crítica de Henry}

Neste tópico, damos maior rigor epistemológico a uma crítica localizada: na leitura de Henry (2013, p. 90), “querer a morte de alguém não é um crime, mas sim o fato de ter matado alguém".

Conforme a disposição teórica sobre a construção de uma leitura, em Ducrot que envolve sempre complexos de acontecimentos, mas minimamente dois: o dizer (posto/pressuposto) e a interpretação desse dizer (o subentendido) -, isolamos duas percepções: pela crítica, Henry entende que o ato jurídico está no acontecimentointerpretação (acontecimento-segundo, do subentendido: "querer a morte de alguém" poderá vir a ser interpretado como crime, se realizado), enquanto que Ducrot entende que o ato jurídico está no acontecimento-posto (acontecimento-primeiro, que instaura posto e pressuposto: enunciar "querer a morte de alguém” é "já" transformar a relação entre estes envolvidos: de querer qualquer outra coisa antes (amar, respeitar, suportar etc), para querer a morte de alguém (exterminar)). Esta transformação imediata, que reconfigura interlocutores e seus sentidos, foi desconsiderada por Henry. 
Temos visto a acuidade de que atos jurídicos (linguísticos) "não julgam", atos jurídicos (linguísticos) transformam relações, obrigam continuidades. Assim, a frase henryana: "querer a morte de alguém" tem minimamente o seguinte potencial transformador de relações: enunciar "querer” é já ser ressignificado no querer, e daí encadear continuidades: “contenho a vontade?” (já sou paciente), “dou vazão à vontade?" (já sou arquiteto de outras opções, uma delas, o crime) etc. A execução de um crime é um acontecimento segundo oriundo de uma transformação primeira: o querer exterminar alguém. $O$ fenômeno linguístico do ato jurídico é tal que o "querer $X$ " não precisa acarretar "o sucesso de X" para significar-se transformação de seus interlocutores. Ao contrário do fenômeno forense do ato jurídico, de Henry. Senão consideremos um análise mais localizada sobre a crítica de Henry:

\section{(2) X quer que $\mathrm{Y}$ morra.}

Tão enunciado (língua em uso) ou frase (língua fora de uso) instaura a seguinte démarche argumentativa (para Ducrot, posto ( $\mathrm{p}$ ), pressuposto (pp) e encadeamento $(\rightarrow)$ nunca são operáveis isoladamente, mas em uma démarche argumentativa que subordina tais espessuras semânticas):

(p): X deseja a morte de $Y$.

(pp): Y está vivo.

Ato jurídico: a relação entre $\mathrm{X}$ e $\mathrm{Y}$ transformou-se, deixando de ser qualquer outro tipo de relação, para se tornar relação perigosa (mesmo que $Y$ não saiba). $O$ enunciado significa, minimamente, tal transformação entre interlocutores. $E$ se alguém vier a saber disso (suponha-se que (2) seja uma fofoca, tal relação entre X, Y, o autor da fofoca, e o ouvinte da fofoca, também terão suas relações ressignificadas, em outras relações).

Alguns encadeamentos $(\rightarrow)$ possíveis entre interlocutores envolvidos em (2): fugir, enfrentar, conviver com, fingir, ignorar, tentar esclarecer, pedir perdão, tentar esquecer, superar, revoltar-se, arquitetar a morte, encomendar a morte, denunciar, processar, matar a sangue frio etc...

(Já estar transformado por) querer a morte, já obriga a encadeamentos próprios. Em todos estes tipos de enunciados encadeados, insiste a (pp) pressuposição "Y está vivo", que incomoda e transformou o locutor desde a primeira enunciação do (p) " $X$ 
quer que $Y$ morra”, e multiplicará seus discursos nesta direção ${ }^{5}$ : os conduz ou obriga a discursivizar em certos lugares e não outros, com certas pessoas e não outras, com certos cuidados e não outros. Fineza argumentativa que escapou ao olhar criminalístico, mas não semântico-linguístico, de Henry.

De passagem, é produtivo rememorarmos a saga, bem ilustrativa deste fenômeno do ato jurídico da pressuposição, do Papa-Léguas e Coyote (ROAD RUNNER, 1949), cujo fio condutor de coerência, em todos os desenhos animados, é o pressuposto fundante e transformador (pp) “o Papa-léguas está vivo", que resiste e insiste em todos os discursos-encadeamentos de tentativas de assassinato, da série. $O$ (pp) do Papa-léguas vivo transformou as relações entre seus interlocutores, o Coyote (sempre o que ameaça) e o Papa-léguas (sempre o que caçoa), e o telespectador, que se interessa (ou se ocupa) dessa perseguição.

Desta forma, Ducrot coloca relevo no fenômeno semântico de que enunciar "querer a morte de alguém” não é crime, mas é enunciado que já transformou/ressignificou relações anteriores, entre $\mathrm{X}$ e $\mathrm{Y}$, e entre $\mathrm{X}$ consigo mesmo, minimamente, e talvez $Y$ consigo mesmo (se $Y$ souber do querer ameaçador).

$O$ refinamento que aqui propomos entre o ato jurídico forense ou pósacontecimento, de Henry, e o ato jurídico linguístico ou intra-acontecimento, de Ducrot, revela que ser partícipe de "X cometeu uma gravidade com alguém”, é ser vítima de ressignificação/transformação em dois momentos, no mínimo (porque o processo de ressignificação e retomada são constantes e sem fim): em um primeiro momento, no ato mesmo da enunciação - o ato jurídico linguístico de Ducrot -, mais ou menos na direção de "fazer algo notório com alguém é ressignificar-me e ressignificar minha relação com este alguém, ali mesmo no próprio ato"; ou em um segundo e demais momentos enunciativos - o subentendido de Ducrot, ou ato jurídico de Henry - que nas sociedades modernas, posteriormente será interpretado/subentendedido, via sujeitos-legitimados para "interpretações oficiais", como: crimes contra o patrimônio, crimes contra a pessoa, crimes contra a honra, crimes contra a administração pública, crimes econômicos etc. Não importa: nenhum deles mudará o fato inicial de efeito transformador da/na língua, que acarretarão ondas variadas da interpretação.

Tal como não se pode arremessar uma pedra ao rio sem que o rio produza ondas, é inevitável que o impacto da pressuposição e da enunciação produzam

${ }^{5}$ É uma das constitutividades da pressuposição argumentativa: a continuidade do dizer. Conforme temos dito (MACHADO, 2021a). 
transformações de relações. A noção do ato jurídico linguístico leva-nos a considerar refinamentos da enunciação, tal que enunciar (ou apenas escutar) é transformar-se neste acontecimento. Mas é igualmente relevante explorar o potencial do ato jurídico no nível da frase, na língua fora de emprego. Consideremos a frase:

(3) João roubou Maria

Considerar a possibilidade da enunciação (a frase) é, para semanticistas refinados, considerar o potencial de transformação de relações da frase, em enunciações possíveis. Trabalhar a significação, em Ducrot, é considerar o potencial de desorganização de relações que certa frase carrega. Para Ducrot, o conceito língua, à luz do ato jurídico, é isso: toda frase é propensa a desorganizar quadros organizados. E em termos de semântica, a desorganização é ideia tão ou mais elucidativa quanto a ideia de organização.

Ora, senão vejamos o exercício linguístico dos exímios criminosos. Por exemplo, os psicopatas tramam seus planos no nível da frase (como matarei? Como roubarei? Como enganarei perfeitamente? Como manipularei? Quais palavras usar para transformar/conseguir tais coisas? Etc). Enfim, é este fenômeno estrutural-enunciativo jurídico que Ducrot aponta.

No caso de (3), a démarche argumentativa é tal que, neste ato fictício, no nível da frase, o (p) posto da "autoria do roubo, de João", pressupõe (pp) "Maria foi roubada". Ato pressuposto na frase que muda as relações entre o locutor e interlocutor, quais sejam: a suspeição de João é significação suficiente para abalar as relações entre partícipes virtuais ou leitores de (3).

Por exemplo. Podemos vislumbrar o potencial jurídico-linguístico de (3), minimamente assim: o possível interlocutor de (3 - porque a frase é não-contextual -, pela consideração imediata de (3), contrastará a significação de “João + Maria” antes do roubo (significações de positividades, ou trivialidades, não-invasividades etc), e "João + Maria" depois do roubo (significações imediatas de negatividades, invasividades etc). A palavra "roubo", que organiza a frase (3), impõe que a significação frástica de roubo muda as relações entre o possível ladrão e o possível ouvinte do roubo: mesmo se não se comprovou a causa do furto, João "já é" suspeito, no ato frástico-jurídico. E "já-ser” significado suspeito, na imediata consideração da frase (3), "já-impõe” encadeamentos $(\rightarrow$ ) por sobre a significação de negatividade jurídico-linguística da suspeição de João, diante do pressuposto (pp) "Maria foi roubada”: por exemplo, encadeamento de contraposição (“Não foi!”), concordância 
(“como ele pôde?”), solutiva (“vou falar com a família dele”), prudente (“evitar João”) etc.

Não importa os discursos que se desdobrarão da acusação de (3), o pressuposto que está em todos eles e lhes dá fio de coerência "(pp) Maria foi roubada" "já macula" a significação de João inocente, ressignificando negativamente “João", ali mesmo, na virtualidade de (3). Não é o que vem após (3) que ressignifica relações entre interlocutores. As transformações ocorrem já em (3). O que acontece após (3) é, sim, atividade enunciativa/interpretativa forense: a negatividade "já significada” em (3) será objeto de fortalecimento (acusação) ou de enfraquecimento (defesa). Não importa, as relações entre os partícipes que fizerem uso desta frase (3) já estão postas.

\section{Adendo teórico}

É produtivo traçar um panorama diacrônico, mesmo que sintético, sobre a relação "língua e subjetividade”, na esteira da acusação de Henry (2013, p. 91), segundo a qual Ducrot apenas apaga (o que ele, Henry, entende por) a subjetividade, que outrora Benveniste e Searle introduziram no ato ilocucionário.

Primeira observação - a língua é um conceito de subjetividade. Os trabalhos de Ducrot demonstram que sujeito e a linguagem, e sujeito e enunciação, são inseparáveis quando se define o conceito de língua, em Ducrot. O leitor atento de Ducrot percebe que a improcedência dessa acusação consta de uma leitura insuficiente do conceito de língua, em Ducrot (em alguns trechos, Henry apresentou interpretações deveras discrepantes das definições ducrotianas, por exemplo, em Dire et ne pas dire).

De partida, o conceito de língua ducrotiano não estabelece que se se isole signo e emprego do signo (separar a frase do enunciado, para Ducrot), muito menos que se isole o sujeito, língua, e as miríades de desdobramentos subjetivos, desse imbricamento. Ao contrário, a essência argumentativa da língua exige que ela carregue, nas suas estruturas, marcas da enunciação. E como não há enunciação sem sujeito - ora, alguém deve enunciar para que seja enunciação -, como não há possibilidade de língua sem previsão mínima de um sujeito que use tal língua, é indesviável que o conceito de língua consiste em um conceito fortemente determinado por sujeitos linguísticos: significados, prefigurados e calculáveis, na língua; e particularizados por contextos e situações, na enunciação. A língua em Ducrot é, portanto, um conceito de subjetividade e que produz subjetividade, porque para a 
Semântica Argumentativa, não há enunciação sem sujeito, nem língua sem cálculo de usuário de língua.

Segunda observação - a significação: conceito de inclusão, não de exclusão. A língua, pela epistemologia semântico-argumentativa, possui, em si, enquanto constitutividade, relações de significação tão ilimitadas que é difícil traçar um corte de exclusão forte - e isso não descategoriza um método estrutural enunciativo. E nós estamos criticando, aqui, autores que tomam o nome de Ducrot para isolar, com enorme facilidade, elementos que "eles acreditam que Ducrot isolaria". Uma leitura atenta do acervo ducrotiano sob a égide da significação desvela que a língua, em Ducrot, não é artefato de museu, engessado, codificações limitadas. Desde sempre Ducrot se esforçou para refutar essa definição limitadíssima de língua. Língua é movimento que se fez artefato (e por isso ainda é movimento). Língua são pistas da enunciação marcadas no enunciado. É importante, para trabalhar com Ducrot (e Semântica Argumentativa), reter o raciocínio bussolar de que o uso que se tornou signo está no signo, e deve ser considerado "no" signo. Pois usar um nome pressupõe aceitar o mundo e os objetos desse nome.

Um exemplo: todo o (dificilmente delimitável) uso da estrutura "alta velocidade" está contido nessa expressão: a existência de um perigo, a possibilidade de acidente, certa dinâmica de veículo, certa disposição que acarreta que se deveria ter certa estrada/rodovia, certo grau de atenção do condutor, possibilidade de vítimas, exigência de boas frenagens etc. Assim, considerar a frase "João está em alta velocidade" é considerar isso tudo, inclusive os sujeitos desse potencial dizer; e enunciar “João está em alta velocidade”, é particularizar tudo isso, e dizer muito mais. Pois para Ducrot (1977, p. 247), "o nome empregado substantivamente, institui sempre, para fazer dele a moldura do diálogo, um mundo de objetos, o que equivale segundo nossa definição do pressuposto, a dizer que ele pressupõe a realidade de um mundo desse tipo". Temos vários domínios que imbricam e significam na única expressão, "alta velocidade". Estamos falando, portanto, de um conceito de significação includente, porque semântico, e não excludente, porque fragmentado em más leituras estruturalistas. Aliás, falar em estruturalismo, em semântica(s), já é guardar as "tesouras" e "as facas" mais apressadas. Porque o corte, em semântica, é habilidade cuidadosa e enganosa, labuta para altos chefs que se ocupam dos "fugus"6 linguísticos.

\footnotetext{
${ }^{6}$ Metaforizamos o suposto (e exagerado) corte estruturalista com o fugu: o fugu, ou baiacu, é peixe da alta culinária japonesa, manejável por apenas pouquíssimos profissionais certificados e treinados. Se cortado erroneamente, leva à morte. Se cortado corretamente, é fina iguaria.
} 
Neste eco, a subjetividade (relações sujeito e linguagem) nunca foi excluída por Ducrot, mas foi refletida e debatida exaustivamente no imbricamento estrutural enunciativo (enunciação, enunciado e frase), e por outros nomes teóricos, que sumarizamos de forma mais sucinta, assim:

- momento Standard: a relação sujeito e linguagem foi tratada pelas noções de interlocutor, locutor, ouvinte, acontecimento, posto e pressuposto (porque é sempre alguém que põe, e alguém que pressupõe) etc, enquanto seres argumentativos do discurso e previstos na língua;

- momento Standard ampliado (após a crítica de Henry): os seres polifônicos lâmbida, enunciadores, locutores e interlocutores (DUCROT, 1987), e topoï (DUCROT, 1989);

- momento Blocos Semânticos: quando da atualização da teoria polifônica, a Teoria da Argumentação Polifônica (TAP) ocupou-se das questões do sujeito na relação com a linguagem e a enunciação, por conceitos como: unidade discursiva, atitudes do locutor, e pessoas do discurso (CAREL, 2011);

- momento Cours de Sémantique Argumentative (muito recentemente): hoje, o eco de refinamento de meio século da Semântica Argumentativa explora a subjetividade pelos conceitos de funções textuais, modos enunciativos, argumentações enunciativas (BEHE et al, 2021), além de manter os conceitos de locutor e interlocutor.

\section{Considerações finais}

Esta pesquisa ocupou-se da incompatibilidade entre objeto da crítica (ato jurídico linguístico) e crítica ao objeto (ato jurídico não-linguístico), tal como apresentados e descritos no livro de Paul Henry ([1977], 2013), La mauvais outil: langue, sujet et discours.

Ao refletir linguisticamente tal incompatibilidade, espera-se, com o presente artigo, desconstruir um equívoco para tornar mais coerente um propósito. $O$ equívoco que se pretendeu desconstruir é aquele de abordar um objeto teórico argumentativo (o ato jurídico "na" língua e "na” enunciação, dito ato jurídico linguístico) por um tratamento não-argumentativo (o ato jurídico não-linguístico, ou ato interpretativo pós-acontecimento, ou ato jurídico forense, ou outras leituras de atos jurídicos). O que acarreta afastar-se do objeto que se crê aproximar, quando na verdade instaura-se outros nortes, via outros objetos não-linguísticos, com as quais as críticas não se sustentam. 
O propósito que se tentou dar coerência, é a correta abordagem argumentativa do ato jurídico, que recupera as determinações da língua, em Ducrot.

Henry não explorou as minúcias semântico-argumentativas do fenômeno de linguagem, previstas no conceito de língua ducrotiano, conceito estrutural-enunciativo que jamais exclui fala (e sua riqueza) da língua (e sua riqueza), conceito que integra enunciação ao enunciado desde a década de 70, e nesse movimento, a Semântica Argumentativa leciona que língua serve não para comunicar, mas serve, minimamente, para transformar relações (e ressignificar relações) entre interlocutores, através do que se diz.

Enquanto resultados objetivos, podemos destacar que este estudo conclui que criticar o ato jurídico de Ducrot é compreender a profundidade nada óbvia do conceito de língua ducrotiano. Trabalhos que se carecem no Brasil. A ilegitimidade de certas críticas desfaz-se por um tratamento teórico de se abordar adequadamente o conceito de língua em Ducrot, enquanto objeto que indissocia: o dizer das normas de dizer (leis de discurso), o explícito do implícito (posto e pressuposto), o dizer do potencial de continuação do dizer (encadeamentos), o dizer das transformações instauradas pelo dizer (ato jurídico), e o potencial semântico de certa língua do sentido efetivamente produzido por essa língua (a descrição da enunciação via conceitos de sentido e significação).

Por fim, enfatiza-se, a discussão está longe de se fechar. Contraexemplos desafiam os arcabouços teóricos, prática da atualização em ciências de linguagem, mas a percepção semântica do adjetivo “jurídico” por sobre a língua e práticas enunciativas insiste em exemplos bem formados, e resiste aos "mal formados". Afinal, o dizer, com seus semantismos e sentidos, de alguma forma (mesmo que ainda não se possa formalizar técnico e adequadamente como), transforma relações entre interlocutores. Ou como corrobora o folk linguistic da sabedoria oriental, palavra dita é flecha lançada, nunca volta, porque dizer é transformar.

\section{REFERÊNCIAS}

BALLY, Charles; SECHEHAYE, Albert. Ferdinand de Saussure: Cours de Linguistique Générale. Paris: Payot, 1985.

BEHE, Louise; CAREL, Marion; DENUC, Corentin; MACHADO, Julio Cesar. Cours de Sémantique Argumentative. Pedro \& João Editores, 2021, no prelo.

CAREL, Marion. L'entrelacement Argumentatif: lexique, discours et blocs sémantiques. Paris: Honoré Champion, 2011. 
CAREL, Marion; RIBARD, Dina. L'acte de témoigner. Antares - Letras e Humanidades, v. 11, $\mathrm{n}$. 23, p. 3-23, 2019.

DELOOR, Sandrine. Bref aperçu historique des travaux sur la présupposition. Langage, n. 186, v. 2, p. 3-20, 2012.

DUCROT, Oswald. Qu'est-ce que le structuralisme? Le Structuralisme en linguistique. Paris: Éditions du Seuil, 1968.

DUCROT, Oswald. Dire et ne pas dire. Principes de sémantique linguistique. Paris: Hermann, 1972.

DUCROT, Oswald. Dizer e não dizer: princípios de semântica linguística. Tradução: Carlos Vogt. São Paulo: Cultrix, 1977.

DUCROT, Oswald. Les echelles argumentatives. Paris: Les Editions de Minuit, 1980.

DUCROT, Oswald. 0 dizer e o dito. Revisão técnica da tradução: Eduardo Guimarães. Campinas: Pontes, 1987.

DUCROT, Oswald. Argumentação e “Topoi” argumentativos. In: GUIMARÃES, Eduardo. História e Sentido na Linguagem. Campinas: Pontes, 1989. p. 13-38.

DUCROT, Oswald; SCHAEFFER, Jean-Marie. Nouveau dictionnaire encyclopédique des sciences du langage. Paris: Éditions du Seuil, 1995.

GOMES, Lauro. Discurso artístico e argumentação. Campinas: Pontes, 2020.

HENRY, Paul. A ferramenta imperfeita: língua, sujeito e discurso. Campinas: Unicamp, 2013.

LEBLER. Cristiane Dall Cortivo. Pressupostos e subentendidos segundo a Teoria da Argumentação na Língua. Gragoatá, Niterói, n. 40, p. 295-316, 2016. Disponível em https://periodicos.uff.br/gragoata/article/view/33385/19372. Acesso em: 14 abr 2021.

MACHADO, Julio Cesar. O paradoxo a partir da teoria dos blocos semânticos: língua, dicionário e história. Tese (Doutorado em Linguística) - Universidade Federal de São Carlos, UFSCar, 2015.

MACHADO, Julio Cesar. 50 anos da pressuposição na semântica argumentativa: análises do fenômeno pressuposicional de 1968 a 2018. Cadernos de Estudos Lingüísticos, Campinas, v. 61, p. 1-21, 2019. DOI: http://doi.org/10.20396/cel.v6111.8652865

MACHADO, Julio Cesar. A pressuposição-defeito de Paul Henry e a pressuposição argumentativa de Oswald Ducrot: um fenômeno que insiste e resiste, 2021a, no prelo.

MACHADO, Julio Cesar. O estruturalismo enunciativo de Oswald Ducrot: o que (não) é, 2021b, no prelo.

MORAES, Érika de. Teorias semânticas e a implicitação na língua(gem). Alfa, São Paulo, v. 53, n. 1, p. 261-282, 2009. Disponível em: https://periodicos.fclar.unesp.br/alfa/article/view/1687. Acesso em: 14 abr 2021.

SOARES, Verônica de Fátima Camargo. Pressuposição: diferentes abordagens teóricas e suas consequências para o ensino de graduação em letras. Dissertação (Mestrado em Linguística) - Universidade Federal do Espírito Santo. 2012. Disponível em https://repositorio.ufes.br/handle/10/3754. Acesso em: 14 abr 2021. 